
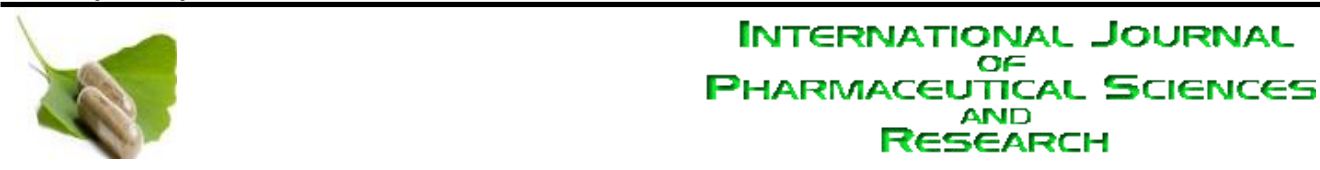

Received on 27 April, 2011; received in revised form 26 July, 2011; accepted 28 September, 2011

\title{
A SIMPLE UV SPECTROPHOTOMETRIC METHOD FOR THE DETERMINATION OF FEBUXOSTAT IN BULK AND PHARMACEUTICAL FORMULATIONS
}

Paramdeep Bagga, Mohd Salman, H. H. Siddiqui*, Abdul M. Ansari, Tariq Mehmood and Kuldeep Singh

Faculty of Pharmacy, Integral University, Kursi Road, Lucknow, Uttar Pradesh, India

Keywords:
Febuxostat,
Absorbance,
Validation,
Detection Limit
H. Siddiqui
ice-Chancellor \& Hon.
Pharmacology, faculty of
Itegral University, Kursi Road,
tar Pradesh, India

Correspondence to Author:

Prof. (Dr) H. H. Siddiqui

Advisor to Vice-Chancellor \& Hon. Professor of Pharmacology, faculty of pharmacy, Integral University, Kursi Road, Lucknow, Uttar Pradesh, India

\section{ABSTRACT}

A simple and cost effective spectrophotometric method is described for the determination of febuxostat in pure form and in pharmaceutical formulations. The drug was highly soluble in methanol so it was selected as the solvent system for the drug. This ensured adequate drug solubility and maximum assay sensitivity. The linearity range for febuxostat at its wavelength of detection of $315 \mathrm{~nm}$ was obtained as $0.2-15 \mu \mathrm{g} / \mathrm{ml}$. The linear regression equation obtained by least square regression method, were $Y$ $=0.0802 . X+0.0036$, where $Y$ is the absorbance and $X$ is the concentration (in $\mu \mathrm{g} / \mathrm{ml}$ ) of pure drug solution. The absorbance was found to increase linearly with increasing concentration of febuxostat, which is corroborated by the calculated correlation coefficient value of 0.9999 . The limit of detection and limit of quantification was found to be $0.1743 \mu \mathrm{g} / \mathrm{ml} \& 0.5281 \mu \mathrm{g} / \mathrm{ml}$ respectively. The validity of the described procedure was assessed. Statistical analysis of the result shows high accuracy and good precision. The proposed method was successfully applied to the determination of febuxostat in pharmaceutical formulations without any interference from common excipients.
INTRODUCTION: Febuxostat chemically is 2- [3- cyano4- (2- methlypropoxy) phenyl]- 4- methlythiazole- 5 carboxylic acid (Figure 1). It is a non purine selective inhibitor of xanthine oxidase that is indicated for use in the treatment of hyperuricemia and gout ${ }^{1}$.

In contrast to allopurinol, febuxostat inhibits both oxidized and reduced forms of xanthine oxidase ${ }^{2,3}$ and has minimal effects on other enzymes of purine and pyrimidine metabolism 3, 4. A study comparing febuxostat to allopurinol found that more individuals treated with febuxostat had decreased levels of uric acid, but there was no difference in the amount of initial gout flares or the surface area of gout tophi ${ }^{5}$.

Literature survey revealed only one hplc method for the estimation of febuxostat and its related substances
${ }^{6}$. The aim of the study is to develop a simple, sensitive, accurate and precise method for determination of febuxostat in pharmaceutical formulations and bulk drugs using UV spectrophotometer.

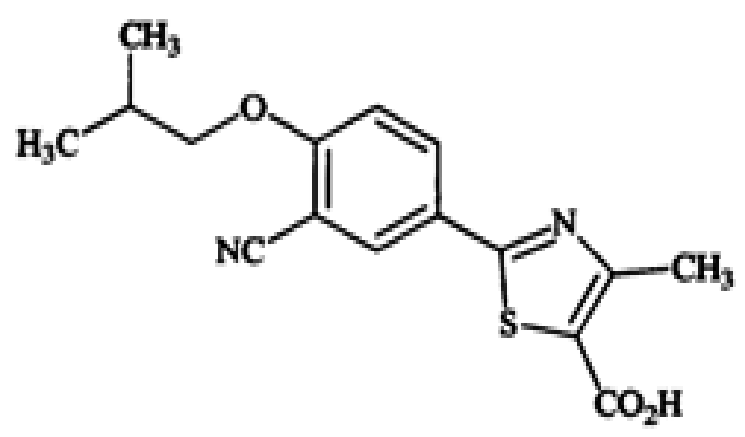

FIG. 1: STRUCTURE OF FEBUXOSTAT 


\section{Experimental:}

Instruments: A Shimadzu UV- Visible Spectrophotometer (UV-1700) with a matched pair of $10 \mathrm{~mm}$ quartz cells were used for experimental purpose. Shimadzu AUX-220 balance was used for weighing the samples.

Materials: Febuxostat was obtained as a gift sample from Lupin Limited, Vadodara (Batch No. 16/NV07/09). Methanol AR was procured from RFCL Limited, New Delhi. The commercially available marketed tablet brand containing Febuxostat, $40 \mathrm{mg}$ in each tablet have been used for estimation.

\section{Scanning and determination of maximum wavelength}

$\left(\boldsymbol{\lambda}_{\max }\right)$ : In order to ascertain the wavelength of maximum absorption ( $\lambda$ max) of the drug, qualitative solution of the drug was prepared in methanol and scanned using UV spectrophotometer within the wavelength region of $200-400 \mathrm{~nm}$ against methanol as blank. The resulting spectra are shown below (Fig. 2) and the absorption curve showed characteristic absorption maxima at $315 \mathrm{~nm}$ for Febuxostat.

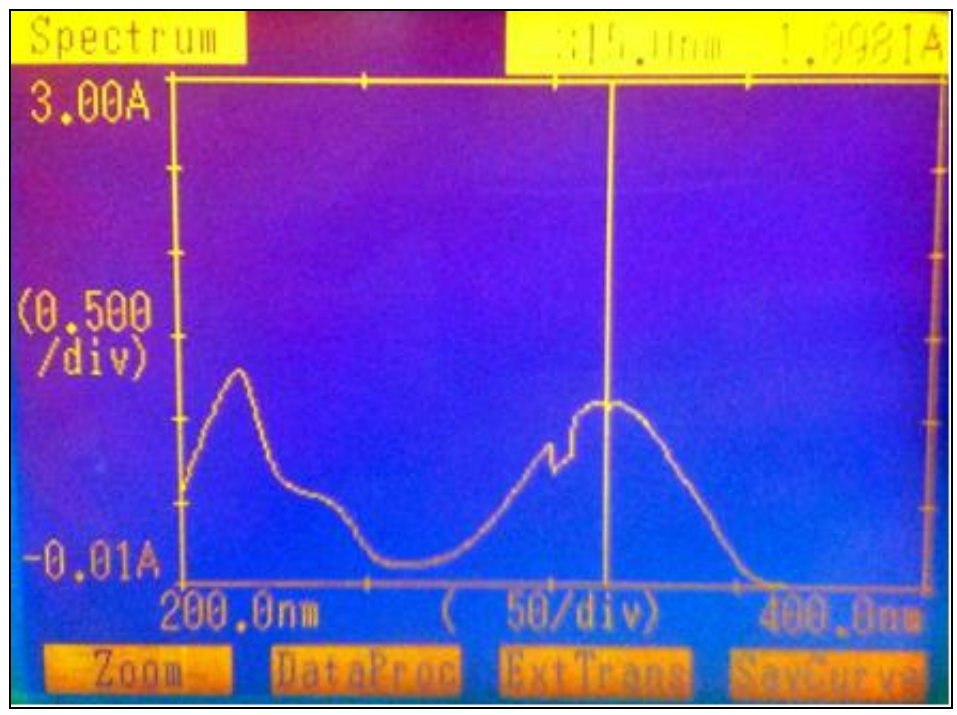

FIG. 2: SPECTRUM OF FEBUXOSTAT (200-400nm)

Preparation of Standard Stock Solutions: Standard stock solution (primary) was prepared by dissolving 10 $\mathrm{mg}$ of febuxostat in $10 \mathrm{ml}$ of methanol to get concentration of $1 \mathrm{mg} / \mathrm{ml}(1000 \mu \mathrm{g} / \mathrm{ml})$ and was stored at +4 으 $\mathrm{C}$ during the study. Secondary stock solution was prepared daily by diluting $1 \mathrm{ml}$ of the primary stock solution to final volume of $10 \mathrm{ml}$ using methanol to get concentration of $0.1 \mathrm{mg} / \mathrm{ml}(100 \mu \mathrm{g} / \mathrm{ml})$.
Preparation of calibration standard solutions: The calibration standard solutions were prepared daily by diluting secondary stock solution with methanol to get calibration standard solutions of $0.2,0.5,0.8,1,5,10$ and $15 \mu \mathrm{g} / \mathrm{ml}$ of febuxostat to construct Beer's law plot for pure drug, the absorbance was measured at $\lambda$ max $315 \mathrm{~nm}$, against methanol as blank.

Procedure for formulations: Twenty tablets of febuxostat were accurately weighed, finely powdered and mixed. A portion of the powder equivalent to $10 \mathrm{mg}$ of febuxostat was transferred into a $10 \mathrm{ml}$ volumetric flask and $10 \mathrm{ml}$ of methanol was added. The content of the flask was sonicated for $15 \mathrm{~min}$ and diluted to volume with methanol. This solution was centrifuged for $15 \mathrm{~min}$ at $5000 \mathrm{rpm}$ to separate out the insoluble excipients. Appropriate solutions were prepared by taking suitable aliquots of the clear supernatant and diluting them with methanol to give final concentration $(10 \mu \mathrm{g} / \mathrm{ml})$. The absorbance of these solutions was measured at $315 \mathrm{~nm}$. The amount of febuxostat per tablet was calculated using the calibration curve.

Validation: Validation is one of the most important steps in method development for analytical determinations. The main validation parameters ${ }^{7}$ such as linearity and range, accuracy and precision, limit of detection (LOD), limit of quantitation (LOQ), recovery and ruggedness were evaluated in developed method.

Linearity \& Range: Under the experimental conditions, the calibration graphs of the absorbance versus concentration were found to be linear over the range of $0.2-15 \mu \mathrm{g} / \mathrm{ml}$ for proposed method. The statistical analysis of data obtained for the estimation of febuxostat in pure solution indicated high level of accuracy for the proposed methods as evidenced by the low values of standard deviation and coefficient of variation (Table 1).

The linear regression equation obtained was $\mathrm{Y}=$ $0.0802 . X+0.0036$, where $Y$ is the absorbance and $X$ is the concentration (in $\mu \mathrm{g} / \mathrm{ml}$ ) of pure drug solution (Figure 3). Linearity of the regression equation and negligible scatter of points for the two drugs by the proposed methods were demonstrated from the highly significant $(p>0.05)$ correlation coefficient value. 
The reported slope values without intercept on the ordinate at $95 \%$ confidence limits, suggested that the calibration lines of febuxostat solutions in methanol did not deviate from the origin as the above-obtained values fall within the confidence limits. (Table $\mathbf{2}$ )

TABLE 1: LINEARITY TABLE OF FEBUXOSTAT IN WORKING STANDARD

\begin{tabular}{cccc}
\hline Conc. $(\mu \mathrm{g} / \mathrm{ml})$ & Mean Absorbance & Std. Error & \%CV \\
\hline 0.2 & $0.0166 \pm 0.0003$ & 0.0002 & 1.8367 \\
0.5 & $0.0447 \pm 0.0007$ & 0.0004 & 1.4907 \\
0.8 & $0.0636 \pm 0.0005$ & 0.0003 & 0.7760 \\
1.0 & $0.0863 \pm 0.0004$ & 0.0002 & 0.4685 \\
5.0 & $0.4068 \pm 0.0010$ & 0.0006 & 0.2462 \\
10.0 & $0.8106 \pm 0.0013$ & 0.0008 & 0.1604 \\
15.0 & $1.2016 \pm 0.0015$ & 0.0008 & 0.1213 \\
\hline
\end{tabular}

* Average of three determinations with standard deviations; CVCoefficient of variation

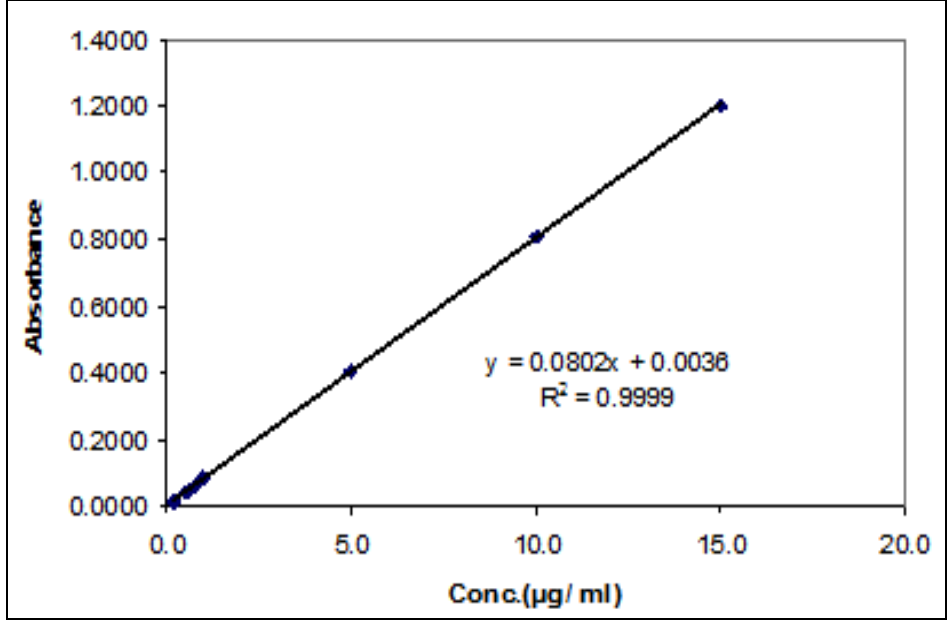

FIG. 3: LINEARITY CURVE OF FEBUXOSTAT

TABLE 2: REGRESSION ANALYSIS OF DATA FOR THE ESTIMATION OF FEBUXOSTAT FROM STANDARD SOLUTION

\begin{tabular}{cc}
\hline Statistical Parameters & Febuxostat \\
\hline Regression equation & $\mathrm{Y}=0.0802 \mathrm{X}+0.0036$ \\
Correlation coefficient & 0.9999 \\
Molar absorptivity, L mol-1 cm-1 & $2.505^{*} 10^{4}$ \\
Standard error of slope & $3.002 \times 10^{-4}$ \\
Standard error of intercept on ordinate & $2.128 \times 10^{-3}$ \\
Standard error of estimate & $4.23 \times 10^{-3}$ \\
95\% confidence interval of slope & $7.938 \times 10^{-2}, 8.09 \times 10^{-2}$ \\
95\% confidence interval of intercept & $-1.869 \times 10^{-3}, 9.073 \times 10^{-3}$ \\
Slope without intercept & $0.0805 \mathrm{X}$ \\
\hline
\end{tabular}

Accuracy: To determine the accuracy of the proposed method, recovery studies were carried out by adding different amounts $(80 \%, 100 \%$, and $120 \%)$ of bulk samples of febuxostat within the linearity range were taken and added to the pre-analyzed formulation of concentration $5 \mu \mathrm{g} / \mathrm{ml}$.From that percentage recovery values were calculated. The results were shown in Table 3.

TABLE 3: ACCURACY READINGS

\begin{tabular}{|c|c|c|c|c|}
\hline \multirow[t]{2}{*}{ Sample ID } & \multicolumn{2}{|c|}{$\begin{array}{c}\text { Concentration } \\
(\mu \mathrm{g} / \mathrm{ml})\end{array}$} & \multirow{2}{*}{$\begin{array}{c}\% \\
\text { Recovery }\end{array}$} & \multirow{2}{*}{$\begin{array}{l}\text { Statistical } \\
\text { analysis }\end{array}$} \\
\hline & Pure drug & Formulation & & \\
\hline S1:80\% & 4 & 5 & 100.3 & Mean $=100.58$ \\
\hline S2:80\% & 4 & 5 & 102.6 & \\
\hline S3:80\% & 4 & 5 & 99.5 & $S D=1.24$ \\
\hline S4:80\% & 4 & 5 & 99.2 & \\
\hline S5:80\% & 4 & 5 & 100.7 & $\% R S D=1.23$ \\
\hline S6:80\% & 4 & 5 & 101.2 & \\
\hline S7:100\% & 5 & 5 & 99.6 & Mean $=99.83$ \\
\hline S8:100\% & 5 & 5 & 99.7 & \\
\hline S9:100\% & 5 & 5 & 99.2 & $S D=0.44$ \\
\hline S10:100\% & 5 & 5 & 100.1 & \\
\hline S11:100\% & 5 & 5 & 100.3 & $\% \mathrm{RSD}=0.44$ \\
\hline S12:100\% & 5 & 5 & 100.1 & \\
\hline S13:120\% & 6 & 5 & 98.2 & Mean $=99.23$ \\
\hline S14:120\% & 6 & 5 & 98.9 & \\
\hline S15:120\% & 6 & 5 & 98.4 & $S D=1.01$ \\
\hline S16:120\% & 6 & 5 & 99.1 & \\
\hline S17:120\% & 6 & 5 & 99.9 & $\% \mathrm{RSD}=1.02$ \\
\hline S18:120\% & 6 & 5 & 100.9 & \\
\hline
\end{tabular}

$\%$ Recovery = (amount recovered/amount introduced) $\mathrm{X} 100$

Precision: The precision of a method is defined as the closeness of agreement between independent test results obtained under optimum conditions. Three different concentrations of Febuxostat in the linear range $(0.6,3$ and $12 \mu \mathrm{g} / \mathrm{ml})$ were analyzed in 5 independent series in the same day (intra-day precision) and 3 consecutive days (inter-day precision). The precision of the analysis was determined by calculating the relative standard deviation (RSD \%). The results are shown in Table 4 \& 5 .

TABLE 4: INTRADAY PRECISION READINGS READINGS $(n=5)$

\begin{tabular}{cccc}
\hline & Conc. $(\mu \mathrm{g} / \mathrm{ml})$ & Mean \pm SD & \%RSD \\
\hline Day 1 & & $0.0513 \pm 0.0007$ & $1.45 \%$ \\
Day 2 & \multirow{2}{*}{0.6} & $0.0509 \pm 0.0010$ & $2.05 \%$ \\
Day 3 & & $0.0516 \pm 0.0005$ & $1.03 \%$ \\
\hline Day 1 & & $0.2469 \pm 0.0040$ & $1.62 \%$ \\
Day 2 & \multirow{2}{*}{$0.2502 \pm 0.0046$} & $1.84 \%$ \\
Day 3 & & $0.2511 \pm 0.003$ & $1.98 \%$ \\
\hline Day 1 & & $0.9766 \pm 0.0010$ & $0.10 \%$ \\
Day 2 & \multirow{2}{*}{12} & $0.9770 \pm 0.0008$ & $0.08 \%$ \\
Day 3 & & $0.9783 \pm 0.0025$ & $0.26 \%$ \\
\hline
\end{tabular}


TABLE 5: INTERDAY PRECISION READINGS READINGS ( $n=5)$

\begin{tabular}{ccc}
\hline \multirow{2}{*}{ Conc. $(\mu \mathrm{g} / \mathrm{ml})$} & Interday & Precision \\
\cline { 2 - 3 } & Mean \pm SD & \%RSD \\
\hline 0.6 & $0.0513 \pm 0.0008$ & 1.5804 \\
3 & $0.2494 \pm 0.0046$ & 1.8623 \\
12 & $0.9773 \pm 0.0017$ & 0.1741 \\
\hline
\end{tabular}

Detection Limit \& Quantitation Limit: The detection limit of an individual analytical procedure is the lowest amount of analyte in a sample which can be detected but not necessarily quantitated as an exact value. The quantitation limit of an individual analytical procedure is the lowest amount of analyte in a sample which can be quantitatively determined with suitable precision and accuracy. The LOD and LOQ were calculated by using the relation $3.3 \sigma / \mathrm{S}$ and $10 \sigma / S$ respectively, where $\sigma$ is the standard error of estimate and $S$ is the slope. Calculated values of limit of detection (LOD) and quantitation (LOQ) for Febuxostat were found to be 0.1743 and $0.5281 \mu \mathrm{g} / \mathrm{ml}$ respectively.

Ruggedness: The ruggedness of the proposed method was evaluated by applying the developed procedures to assay of $10 \mu \mathrm{g} / \mathrm{ml}$ of febuxostat using the same instrument by two different analysts under the same optimized conditions at different days. The obtained results were found to reproducible, since there was no significant difference between analysts. Thus, the proposed methods could be considered rugged (Table 6).

TABLE 6: RUGGEDNESS DATA AT 10 MG/ML BY TWO ANALYSTS AT DIFFERENT DAYS

\begin{tabular}{ccc}
\hline Test Conc. & $\begin{array}{c}\text { Amount Recovered } \\
(\mu \mathrm{g} / \mathrm{ml}) \text { Analyst I }\end{array}$ & $\begin{array}{c}\text { Amount Recovered } \\
(\mu \mathrm{g} / \mathrm{ml}) \text { Analyst II }\end{array}$ \\
\hline & 9.7920 & 9.7465 \\
$10 \mu \mathrm{g} / \mathrm{ml}$ & 9.7944 & 9.8818 \\
& 9.7969 & 9.9002 \\
& 9.9915 & 9.8879 \\
& 9.9841 & 9.9248 \\
Mean & 9.9866 & 9.9039 \\
\hline SD & 9.8909 & 9.8742 \\
\%RSD & 0.1057 & 0.0643 \\
\hline
\end{tabular}

Analysis of pharmaceutical formulations:The optimized spectrophotometric method was applied to the direct determination of Febuxostat in tablet using calibration curve method without any sample extraction or filtration. From the absorbance value, the drug content per tablet (on an average weight basis) was calculated. The results are shown in Table 7.

TABLE 7: ANALYSIS OF PHARMACEUTICAL FORMULATION

\begin{tabular}{ccccc}
\hline & & \multicolumn{3}{c}{ UV Spectrophotometric Method } \\
\cline { 3 - 5 } Formulation & Labelled Amount $(\mathbf{m g})$ & Amount Recovered* $(\mathbf{m g})$ & \% Drug Recovered & \%RSD \\
\hline \multirow{2}{*}{ Furic $^{\circledR}$ Tablets } & \multirow{2}{*}{$40 \mathrm{mg}$} & $39.8084 \pm 0.0103$ & 99.521 & 1.032 \\
\hline
\end{tabular}

*Mean of six determinations

CONCLUSION: In this study a simple, fast and reliable UV spectrophotometric method was developed and validated for the determination of Febuxostat in bulk drug \& pharmaceutical formulations. This method was applied directly to the analysis of pharmaceutical dosage forms without the need for separation such as extraction steps prior to the drug analysis. As this proposed method has the lowest LOD value and wider linear range is more sensitive method. From the results obtained, we concluded that the suggested method showed high sensitivity, accuracy and precision. Moreover, this method is simple and inexpensive and it can be employed for the routine quality control of Febuxostat in pharmaceutical formulations.

ACKNOWLEDGEMENTS: Authors are thankful to Prof. S. W. Akhtar, Honourable Vice Chancellor, Integral
University, Lucknow, for providing necessary facilities for the work. Authors also thankful to $\mathrm{M} / \mathrm{S}$ Lupin Limited, Vadodara for providing the gift sample of Febuxostat.

\section{REFERENCES:}

1. Effect of TEI-6720, a xanthine oxidase inhibitor, on the nucleoside transport in the lung cancer cell line A549. Pharmacology 2000; 60:34-40.

2. Okamoto K, Eger BT, Nishino T, Kondo $S$ and Pai EF: An extremely potent inhibitor of xanthine oxidoreductase: crystal structure of the enzyme-inhibitor complex and mechanism of inhibition. J. Biol. Chem. 2003; 278:1848-1855.

3. Takano $\mathrm{Y}$, Hase-Aoki $\mathrm{K}$, Horiuchi $\mathrm{H}$, Zhao L, Kasahara $\mathrm{Y}$ and Kondo S: Selectivity of febuxostat, a novel non-purine inhibitor of xanthine oxidase/xanthine dehydrogenase. Life Sci. 2005; 76:1835-1847.

4. Yamamoto T, Moriwaki Y, Fujimura $Y$, Takahashi S, Tsutsumi Z and Tsutsui T: Stamp LK, O'Donnell JL and Chapman PT: 
Emerging therapies in the long-term management of hyperuricaemia and gout. Internal medicine journal 2007; 37(4): 258-266.

5. Becker MA, Schumacher HR and Wortmann RL: Febuxostat compared with allopurinol in patients with hyperuricemia and gout. N. Engl. J. Med. 2005; 353 (23): 2450-2461.

6. Cong Z, Shao-jie W, Rong-li MA, Ping $M$ and Tian-hong Z: Determination of content of febuxostat and its related substances by HPLC. Journal of Shenyang Pharmaceutical University 2010; 27(08):648-651.

7. $\mathrm{ICH}, \mathrm{Q} 2$ (R1), Validation of Analytical Procedures: Text and Methodology International conference on Harmonization, Geneva 2005; 1-13. 